\title{
1. Introduction to Sustainable Consumption, Production and Supply Chain Management
}

While the future of our economic system has been under increasing scrutiny for some time - particularly in the context of sustainability thinking the Covid-19 crisis of 2020 has brought a rethink of our current practices once again to the fore. To what extent is our current way of consuming, producing and moving stuff about actually sensible and do we perhaps need to rethink all this and the way we do business, as well as the kind of businesses we run? Since the innovative but mostly overlooked work by Field and Conn (2007) carried out on behalf of the Royal Society of Arts on the topic of 'Tomorrow's Company', attempts to apply recent ecological thinking to the problems of business have remained on the margins of business academic approaches. Yet more recently, we see the existing approach to business sustainability increasingly being challenged from within the business sustainability literature itself for failing to engage with the true nature of the sustainability concept (cf. Winn and Pogutz, 2013; Hahn et al., 2017; Tregidga et al., 2018). In fact, these authors show that due to the unreceptive nature of academic journals to such, of necessity, multi- or interdisciplinary work, where it does exist, this often tends to be in book form (Tregidga et al., 2018: 321). Similarly, Field and Conn's work was not widely disseminated, for, as with many such works, it found a home in the biology literature, rather than the business literature, despite its potential relevance to the latter. This book argues, therefore, that in order to engage properly with sustainability, the sustainable business literature has to engage with the science behind it and therefore with the relevant scientific literature; but also that the very essence of ecological thinking should be internalised in business in order to facilitate a genuine, deep understanding of the place of business within natural systems, for in reality, economic activity is bounded by society, while human societies themselves are bounded by their natural environment. In this respect, then, it is essential for business disciplines to engage, at least at some level, with ecological thinking in order to play 
their role in any transition to a more sustainable economic system and help create the alternative business models this requires.

Attempts to link human activities with natural processes, as embodied in a broad sense by ecology, have a long history stretching at least back to Malthus (1798), yet recent advances in our understanding of natural 'systems' resulting from advances in ecology have provided a new logic to such approaches (Meadows, 2009). The aim in the brief historical sketch that follows is not for a comprehensive review of the relevant literatures, but instead to visit a selection of representative contributions dealing with the notion of linking human and natural systems over the past 200 years, as a full and comprehensive review of the relevant literature of attempts to link business disciplines with biological sciences is beyond the scope of this book. At the same time, it is important to understand why earlier attempts at integrating ecological and economic models have, mostly, failed, or, at least, have failed to capture the imagination of business academics and have thus failed to enjoy more widespread adoption. It is hoped that this - of necessity brief - overview will suffice in this respect, before advancing some new approaches to these concepts, albeit informed by more recent advances in ecological thinking.

\subsection{ECOLOGY AND BUSINESS: A HISTORICAL PERSPECTIVE}

In an academic sense, the crisis model of environmentalism probably started with Thomas Malthus and his work on the dangers of unrestrained population growth (Malthus, 1798). Building on this notion, economist John Stuart Mill (1848) assumed that humanity would limit consumption voluntarily to develop what we would now describe as a 'steady-state' economy within planetary boundaries, a notion later dismissed by neoclassical economists with their reliance on 'the market' to solve such problems. However, Darwin was also influenced by Malthus, thus adding legitimacy to any subsequent attempts at linking the biological sciences with the various branches of economics and business, something Nelson and Winter also use in defence of their work, adding that this provides economists 'in perpetuity' with the right to borrow ideas from biology (Nelson and Winter, 1982, 9). Notable in this period also is Engels' assertion that our perceived human victories over 'nature' will inevitably come back to haunt us (Engels, 1974).

In 1898 Veblen, in what in the present context could be seen as a landmark contribution, published an article that specifically asked the 
question why economics was not an 'evolutionary' science. He claimed, in fact, to be applying 'post-Darwinian' economics, claims that were contested even at the time, as explored by Hodgson (1992). His notion of evolution effectively focused on the inability of economics to recognise the development of human society in terms of 'cumulative sequence', but instead to regard it as static. This, perhaps, reflects the more limited understanding of evolution at the time (Hodgson, 1992). In reality, understanding of natural systems more generally was still quite limited around the turn of the twentieth century and many useful advances, particularly in ecology, have only occurred in the past few decades. What is significant, however, is the fact that Veblen thought the social sciences, and economics in particular, should look to the biological sciences for guidance and should attempt to incorporate the new scientific findings of the time into their own practices and insights. As Veblen suggested, sociology was more receptive to such ideas, thus McKenzie (1924) argued that human communities are effectively ecological entities, governed by similar processes as elsewhere in nature, although even in sociology this notion has not seen significant subsequent development. Within economics this line of thinking became more marginalised, although some aspects of the need to acknowledge natural systems were recognised at least in the 1920s by Pigou (1920) and his concept of externalities, while Gordon in the 1950s (Gordon, 1954, 1958) pointed out that unassigned property rights affect many elements of the environment, inevitably leading to market failures, which Coase (1988) attempted to solve through the idea of 'Pareto optimality' through negotiated settlements. Environmental economics was grafted onto this tradition within economics, especially resource economics, and it is thus positioned firmly within conventional economics, albeit adding to this a concern for environmental issues by, to a degree, internalising some of these externalities (de Steiguer, 2006). It should be noted that Schumpeter's (1942) notion of 'creative destruction', itself derived from Marxist thinking, also implies a - tacit - reference to biological concepts of growth and decay as part of the 'cycle of life'.

A more serious attempt at incorporating ecological ideas into economics is Nelson and Winter's (1982) concept of the evolutionary theory of the firm. These authors use the concept of evolution primarily to endow economic theory with the concept of change - something already argued for by Veblen - while also noting that companies can survive despite not maximising their activities along orthodox economic lines. This introduces the notion of apparent suboptimality, as explored further below; 
nature often favours resilience over efficiency - a concept we shall be exploring in more detail at various points in the book - and thus takes quite a different approach from modern economic thinking. Although Nelson and Winter's work launched what became known as 'evolutionary economics', its impact on mainstream economics was marginal at best. A few later contributions attempted to build on this broad approach of evolutionary micro-economic notions of the evolution of firms from the perspective of industrial ecology (e.g. Nieuwenhuis and Lämmgård, 2013), although such work benefits from another two decades of work in ecology, in particular the importance of understanding ecosystems as dynamic and understanding the importance of resilience (Holling, 1986; Walker and Salt, 2006), explored further below. The concepts of Innovation Ecosystems (Jackson, 2011) and Ecology of Competition (Moore, 1993, 1997, 2006) could also be mentioned. These are further attempts to apply ecological concepts to business; thus Moore (1997), for example, argues that firms now compete through innovation and distinguishes three 'communities' in any innovation ecosystem - research, development and application - which need to be in balance for any innovation ecosystem to be sustainable. These authors see an innovation ecosystem as featuring continuous circulation of material, information and energy, just like a natural system (Moore, 1993). However, economics struggles at a quite fundamental level to recognise and incorporate the concept of limits to growth (Meadows et al., 1972), such as the 'Planetary Boundaries' concept introduced by Rockström et al. (2009). In response to this fundamental problem, Ecological Economics developed, which positions itself as a multidisciplinary field that not only forms a kind of bridge between ecology and economics, but also seeks to include links to other disciplines, such as psychology. It takes as its subject matter the totality of interactions of humans with their environment, also incorporating a historical perspective, and introduces the concept of 'social-ecological systems' (Rockström et al., 2009; Walker et al., 2002). This strand of work is the most promising thus far in integrating the science of sustainability into business academia (e.g. Whiteman et al., 2013). It is important to emphasise that the ecological approach to business is quite alien to and different from conventional business thinking and certainly very far removed from Milton Friedman's 'the business of business is business' (Friedman, 1970) which in many respects forms the foundation of the current interpretation of the economic model as it applies to business. This has come under increasing scrutiny, particularly since the 2008 recession (Denning, 2013). 
Although the 'ecological' worldview (Krebs, 2008), then, is an alien perspective compared to this, yet some of its principles have already been used in younger business-related disciplines such as industrial ecology. Industrial ecology (IE) explores the interactions and relationships between industrial and ecological systems. IE is partly rooted in systems theory and has long used input-output modelling. IE aims to apply ecological principles observed in nature to industrial processes, as clarified by Shireman (2001). The concept of 'biomimicry' should also be mentioned at this point. It argues that human systems should be inspired by natural systems, but it has thus far largely been confined to areas such as engineering and design. Here structures and materials used in nature have formed the inspiration for man-made materials and structures (Benyus, 1997). One aspect of this, swarm behaviour, is developed in some detail by Miller (2010) and has already found applications in supply chain management (SCM) in the form of Ant Colony Optimisation, which brings us back to Field and Conn (2007), who were among the first to attempt to apply these principles beyond such more concrete examples to the more fundamental way in which business might operate. Attempts to make links from ecology to business may also be illustrated by Tilman's work (Tilman, 2000). He explains, for example, that one reason for the inherent stability of more diverse ecosystems is similar to the lower volatility of more diverse investment portfolios. Because species differ from each other they respond differently to environmental change. The more species this is averaged across, the less variable the total. He further argues that complex natural systems 'highlight the conceptual links between economics and ecology - disciplinary links that must be strengthened if ecological knowledge is to be used to help create a sustainable economy' (Tilman, 2000).

What we have today, then, is a landscape featuring various attempts by existing business disciplines to accommodate the sustainability agenda or to take concepts from ecology in order to apply them in some sense to business, and some hints from ecologists that their work may have relevance for business. Most of these have ultimately been unsuccessful, although some show promise. Daly (1999), himself an economist, is known for his challenges of fellow economists and of economics itself, which he would argue cannot, in its current form, deal with sustainability. Fellow economist Pearce, too, attempted to fuse ecological with economic thinking and was probably the first to suggest that we could combine economic growth with increasing sustainability (1993, Pearce et al., 1989). This was crucial in convincing much of the business com- 
munity to take the environmental agenda seriously. Pearce has probably come closest to marrying the economic with the environmental, but here too the economic has tended to dominate the ecological, underlining Daly's or Krebs' argument that these are fundamentally opposed ways of understanding the world. This view also appears to be shared by Korten $(1995,1998)$, leaving ecological economics as the most credible avenue. However, it still presents itself essentially as a bridge between the two disciplines, ecology and economics. What if we instead integrated business conceptually as an integral part of ecological systems, which, in fact, it is in reality? This book features some - tentative - attempts to start this process of integration.

To the extent that demand drives supply - a notion we shall not leave unchallenged - the structure of this book is as follows: Part I deals with consumption and explores why it is the way it is in the developed world and why that is problematic. Part II deals with the supply side, unsustainable production, by analysing the origins of mass production, specifically of cars, to seek an explanation of why the supply side often seems to drive demand as a result of the pressure to produce to meet minimum economies of scale. In the next part, then, we explore the system that links the two, the supply chains or webs, and assess the issues it faces in taking on board the sustainability agenda. The final part will draw all this together and will draw some general conclusions and suggest ways forward, while also exploring some of the problems with current popular ways of understanding the sustainability concept itself; is 'sustainability' sustainable? Enjoy! 